\title{
Relações família-escola: uma análise da visão de educadores de uma turma de sétimo ano do Ensino Fundamental
}

\section{Family-school relations: An analysis of the vision of a class of seventh grade elementary school educators}

\author{
Juliana Yporti de Sena ${ }^{1}$ \\ julianays21@yahoo.com.br \\ Zenaide de Fátima Dante Correia Rocha ${ }^{2}$ \\ zenaiderocha@utfpr.edu.br \\ David da Silva Pereira ${ }^{3}$ \\ davidpereira@utfpr.edu.br
}

\section{Resumo}

Este trabalho tem por objetivo investigar a integração família-escola segundo a visão dos docentes de uma escola pública da região norte do Paraná. A investigação trata dos princípios da Educação em Direitos Humanos do Parecer CNE/CP n 08/2012 e de como os educadores participam dessa integração, visto que a articulação entre família-escola tem sido um fator influenciador na aprendizagem. A coleta de dados foi realizada com uma pedagoga e seis professores de uma turma de $7^{0}$ ano do ensino fundamental, em uma pesquisa de natureza qualitativa, do tipo documental e através de entrevistas semiestruturadas. A análise e interpretação dos resultados têm por base as concepções de Busetto (2006), Nóvoa (2013), Nogueira e Nogueira (2002) e Nogueira (2006). Espera-se oferecer uma contribuição metodológica de identificação de possíveis relações escolares e suas interferências no processo de ensino e aprendizagem.

Palavra-chave: Educação em Direitos Humanos, Democracia na educação, Relações família-escola, Envolvimento equipe escolar e família, Ensino-aprendizagem.

\begin{abstract}
This paper aims to investigate the family-school integration according to the view of some public school educators located in the north of Paraná state. The research is about the principles of Education on Human Rights established in the Decree CNE/CP no 08/2012, and how the educators participate in this integration, assuming that the articulation between family and school has been having an influence factor in learning. The research has been carried out with one pedagogue and six teachers of an elementary seventh degree class, and it was a qualitative, document type one with semi-structured interview. The analyses and interpretation of results are based on the conceptions of Busetto (2006), Nóvoa (2013), Nogueira and Nogueira (2002) and Nogueira (2006). We expect offering a methodological

\footnotetext{
${ }^{1}$ Mestranda em Ensino de Ciências Humanas, Sociais e da Natureza-Universidade Tecnológica Federal do Paraná, Campus de Londrina.

${ }^{2}$ Professora doutora em Educação da Universidade Tecnológica Federal do Paraná, Campus Londrina.

${ }^{3}$ Professor Doutor em Ciência Política da Universidade Tecnológica Federal do Paraná, Campus Cornélio Procópio, e do Programa de Pós-Graduação em Ensino de Ciências Humanas, Sociais e da Natureza da Universidade Tecnológica Federal do Paraná, Campus de Londrina.
}

Revista Educação Online, n. 19, jun-ago 2015, p.68-83 
contribution for identifying possible school relations and their influence on teaching and learning process.

Keywords: Education on Human Rights, Democracy in School, Family-school relations, School team-family involvement, Teaching and learning

\section{Introdução}

A Educação em Direitos Humanos estabelece que a instituição escolar tenha por função realizar atividades que permitam a integração familiar e da comunidade no âmbito escolar, a partir da qual a escola valorize os traços culturais, sociais, econômicos dos sujeitos que fazem parte do entorno do estabelecimento (BRASIL, 2012).

A partir dos princípios apresentados pelo documento, conhecer as principais problemáticas que circundam as inter-relações escolares faz-se necessário, no sentido de permitir uma verificação real desse tema que é foco de discussão de diversos autores, dentre os quais, elencamos Pierre Bourdieu (1992), a fim de refletir sobre o papel da escola na sociedade. Portanto, como descreve Saviani (1994), as contribuições das teorias crítico-reprodutivistas não tiveram por intenção elaborar estratégias para a educação, mas debater situações antes não discutidas, como fatores de influência nas possibilidades de sucesso na aprendizagem, como os conflitos dentro e fora do espaço escolar, e o papel da família.

Nesse contexto, foram selecionadas três questões levantadas por Nogueira (2006):As instituições escolares criam mecanismos para permitir a integração da família e as escolas? Como esses mecanismos permitem que a família participe do desenvolvimento escolar de seus filhos? E qual a interferência dessas relações no desempenho escolar dos alunos?

Em resumo, trata-se de investigar se há ações que contemplem a integração da família na escola e qual a visão dos docentes referente a essa temática, em sua prática pedagógica, no sentido de qualificar o processo de ensino e aprendizagem.

A investigação teve como ponto de partida a coleta de dados de documentos institucionais, como o Projeto Político Pedagógico (PPP) e o histórico escolar sobre os estudantes. Posteriormente, foi possível delimitar o objeto do estudo, que se pautou na investigação de um estudo de caso de uma turma de sétimo ano e no discurso e percepções dos docentes dessa turma, a respeito da relação famíliaescola e sua interferência no processo de ensino e aprendizagem. 
Portanto, foi utilizada entrevista semiestruturada, com os seis docentes e a pedagoga da turma, na intenção de construir uma base para a interpretação dos dados da análise documental e conhecer a visão dos docentes sobre a relação família e comunidade participante na escola. Os dados foram interpretados mediante análise textual discursiva, à luz de teóricos como Busetto (2006), Nogueira e Nogueira (2002), Nogueira (2006) e Nóvoa (2013).

\section{Fundamentação Teórica}

Para a compreensão das estruturas sociais e suas implicações na instituição escolar, faz-se necessária a utilização das concepções da sociologia, área de estudo que abrange os pressupostos teóricos de definições sociais. Entre seus grandes teóricos, Pierre Bourdieu é um pesquisador que retrata os fenômenos sociais e faz considerações sobre as influências das estruturas da sociedade no âmbito escolar (NOGUEIRA; NOGUEIRA, 2002).Para compreensão das análises de Bourdieu sobre a escola, primeiro devem-se compreender alguns conceitos elaborados por ele, como campo e habitus.

Bourdieu (1992) define campo como espaço no qual ocorrem as interações entre os agentes sociais, por meio de disputas para uma permanência ou ascensão dentro do campo, o que ocorreria através de um jogo hierárquico, simplesmente para a manutenção do poder entre os agentes atuantes desses grupos (BUSETTO, 2006).

Para que seus agentes possam adquirir ferramentas para enfrentar os jogos existentes dentro dos campos, necessitam obter autonomia. Autonomia essa que pode ser obtida de capitais que um campo é capaz de produzir, entre eles, o econômico e cultural (BUSETTO, 2006).

O habitus está relacionado à atuação do sujeito dentro de seu campo, criado por uma cultura social e incorporada por ele, como cita Busetto em seu trabalho, referenciando Bourdieu:

[...] sistemas de disposições duráveis e transponíveis, estruturas estruturantes predispostas a funcionar como estrutura estruturante, isto é, como princípios geradores e organizadores de práticas e representação que podem ser objetivamente adaptadas ao seu objetivo, sem supor que se tenham vista conscientemente tais fins, e o controle expresso das operações necessárias para atingi-los, sem ser em nada o produto da obediência a regras e, sendo tudo isso, coletivamente orquestrada sem ser o produto da ação organizadora de um maestro. (BOURDIEU, 1980, p.88-89 apud BUSETTO, 2006, p.119) 
No âmbito educacional, o campo e o habitus se relacionam criando as possibilidades de sucesso escolar, ou seja, o campo escolar, dependendo das relações da escola, pais, comunidade e de como esses dialogam entre si na busca por uma qualidade educacional. Dessa forma, as funções desenvolvidas pela escola e pela família criam um ambiente favorecedor de sucesso escolar dos estudantes.

Para compreender o porquê da temática da família na escola, devem-se entender as dimensões atuais da sociedade. Nesse sentido, (REBOUL, 1974, apud NÓVOA, 2013, P. 217) faz uma breve citação sobre o assunto:

Nossa civilização está em crise. E o sinal mais convincente é sem dúvida a falência da nossa educação. Pela primeira vez na história, talvez, o homem se reconhece incapaz de educar seus filhos. Nossas prodigiosas descobertas na psicologia, nossas iniciativas pedagógicas, muitas vezes tão interessantes e generosas, não podem evitar essa constatação de fracasso; elas fazem com que o fracasso pareça ainda mais escandaloso.

Nesse contexto, diversas atribuições vêm sendo vinculadas à escola, como ocorre no Parecer CNE/CP n. 08/2012, sobre princípios da Educação em Direitos Humanos (EDH), que estabelece que, na instituição escolar, devem ocorrer, "ações, experiências, vivências de cada um dos/as participantes, múltiplas relações com o entorno e condições socioafetivas" (BRASIL, 2012. p.11).

Os princípios da Educação em Direitos Humanos servem de alicerce para mudanças e transformações sociais. A EDH se baseia em sete princípios: dignidade humana, igualdade de direitos, reconhecimento e valorização das diferenças e das diversidades, laicidade do Estado, democracia na educação, transversalidade, vivência e globalidade e sustentabilidade socioambiental. Apesar de todos os princípios serem essências para modificação da conjuntura social, destacam-se a dignidade humana e democracia na educação como fatores preponderantes para a integração da família na escola.

Segundo o Parecer CNE/CP n. 08/2012, a dignidade humana se refere "a uma concepção de existência fundada em direitos; de acordo com os contextos históricos, sociais, políticos e sociais diversos" (BRASIL, 2012, p.9), ou seja, ao trazer esse debate para o âmbito escolar, o parecer permite que os sujeitos se reconheçam e compreendam seu papel de direito e responsabilidade perante a sociedade.

Quanto à democracia na educação, toma-se por base a "liberdade, igualdade e solidariedade - expressando-se no reconhecimento e na promoção dos direitos Revista Educação Online, n. 19, jun-ago 2015, p.68-83 
civis, políticos, sociais, econômicos, culturais e ambientais" (BRASIL, 2012, p.9). No contexto escolar, para a garantia da democracia na educação, sua construção deve ser coletiva, incluindo todos os agentes sociais envolvidos no desenvolvimento das crianças.

Vale ressaltar que as observações de Bourdieu, quanto ao papel da escola como reprodutora de desigualdades sociais (NOGUEIRA; NOGUEIRA, 2002), é o fator propulsor para reflexão sobre a função de todas as instâncias e agentes sociais que possam interferir no desenvolvimento escolar.

\section{Metodologia}

O procedimento metodológico teve como técnicas de investigação, pesquisa documental, revisão bibliográfica e entrevista semiestruturada. Marconi e Lakatos (2010) definem as seguintes técnicas de pesquisa: pesquisas documentais são dados fornecidos por documentos, caracterizando-se como fontes primárias. A revisão bibliográfica também é composta de documentos, porém de ordem secundária, pois já se encontram em acesso ao público. A entrevista semiestruturada permite ao entrevistador uma variedade de respostas, a partir de uma mesma pergunta e, ao mesmo tempo, confere flexibilidade, podendo surgir novas questões para análise.

Primeiramente, a revisão bibliográfica acerca do tema, serviu de subsídio para conhecer as estratégias desenvolvidas e dificuldades que ainda permeiam 0 assunto. Portanto, foram utilizadas algumas questões propostas por Nogueira (2006, p. 165):

quais são as práticas concretas dos sujeitos através de quais dispositivos estão sendo implementados (obviamente, nos casos que estão sendo implementados)? Quais os efeitos no plano do rendimento e equalização das chances escolares? [...] Essas e outras perguntas estão aguardando respostas que somente terão validade se emanarem pesquisas empíricas rigorosas, que se encarreguem de conhecer a realidade dos discursos e das práticas efetivas dos sujeitos sociais, suas implicações e consequências.

Nesse contexto, o procedimento metodológico se desenvolveu a partir de uma visita preliminar à escola, para conhecimento da realidade do estabelecimento, o que permitiu a escolha do estudo de caso como técnica de investigação de uma turma de sétimo ano. 
A análise documental se constituiu de duas fontes: Projeto PolíticoPedagógico (PPP) e o histórico escolar dos estudantes. Portanto, esses documentos cedidos pela instituição de ensino foram utilizados para serem confrontados com os discursos dos docentes participantes da entrevista semiestruturada.

A entrevista semiestruturada foi aplicada durante uma semana, individualmente, aos professores regentes da turma e à pedagoga responsável, durante a hora-atividade, no próprio recinto escolar. Primeiramente, a entrevista apresentava perguntas norteadoras, porém, ao longo do processo, de acordo com as falas, novas questões foram desenvolvidas, tendo sido selecionadas para análise aquelas mais relevantes em relação à temática. Para análise e interpretação dos dados, foi empregada a análise textual discursiva de (MORAES; GALIAZZI, 2011), à luz de teóricos, como Busetto (2006), Nogueira e Nogueira (2002), Nogueira (2006) e Nóvoa (2013).

Para uma melhor compreensão da análise dos dados, cada entrevistado será mencionado aqui, segundo a identificação ( $\mathrm{P}$ : professor) seguido de número arábico: educação física (P1), geografia (P2), história (P3), ciências (P4), matemática (P5), português (P6) e pedagoga (P7).

\section{Da análise documental}

O Plano Político Pedagógico (PPP) estava em construção durante o período de investigação. Dessa forma, o documento datado de 2012 era o mais recente e possuía alguns projetos e procedimentos, que contemplavam a participação da família e da comunidade no âmbito escolar.

Entre os dispositivos de implementação que competem à participação da família e ou comunidade estão:

- $\quad$ Estimular a sociabilização do educando: através de festas regionais, fazendo parte a equipe pedagógica, alunos e a Associação de Pais, Mestre e Funcionários (APMF).

- Articulação interdisciplinar, percorrendo pontos turísticos da cidade: participando, equipe pedagógica, alunos, pais e APMF Amor exigente: palestra sobre a importância da afetividade da família, com a participação da equipe pedagógica, APMF e pais.

- $\quad$ Promover a sociabilização e melhorar o relacionamento em grupo: através de cursos artesanais e artísticos, seguido de uma feira de oportunidades para a venda dos produtos produzidos.

- $\quad$ Participando, equipe pedagógica, APMF, pais e alunos. Resgate da história da escola e da região onde essa está inserida: Articulado por comemoração do 
"Jubileu de Ouro" e criação de galeria na escola. Envolvendo, APMF, equipe pedagógica, pais e alunos. ${ }^{4}$

Os itens descritos acima se encontram em consonância com os dizeres do Parecer CNE/CP $n^{\circ}$. 08/2012, sobre o princípio da democracia na educação, que define algumas dimensões que os sujeitos devem alcançar, como o envolvimento de todos os agentes sociais no âmbito escolar, para garantir o reconhecimento e a promoção de direitos sociais, culturais, econômicos, entre outros, e permitir que a comunidade, família e escola dialoguem sobre as perspectivas locais, regionais e sociais (BRASIL, 2012).

\section{Dados e discussão}

Quanto à participação na construção do PPP, segundo as falas das docentes P1 e P2, ao longo dos anos, ocorreram apenas reformulações, quando a equipe pedagógica julgava pertinente. Alegaram, ainda, jamais terem visto alguma comunicação ou aproximação da comunidade junto à escola.

Quanto à implementação das medidas presentes no PPP, as docentes relataram que as festas e a semana cultural ocorrem esporadicamente, e não há o envolvimento da comunidade e da família. A docente P1 ilustrou tal assertiva, dizendo que um dos projetos que mantinha certa aproximação com a comunidade era o "Amor Exigente", que havia sido iniciado por uma funcionária da escola, porém, após sua saída, também deixou de existir. A atividade intitulada "Jubileu de Ouro" surgiu como uma proposta realizada por um docente que lecionava a disciplina de história, no intuito de coletar dados sobre o histórico da escola, o que resultou em um evento para professores e alguns ex-alunos, fora do âmbito escolar; não é algo que ocorre com frequência.

Esses relatos demonstram que a promoção de inclusão da comunidade na escola ainda está somente no "papel", ou seja, apenas descritos no PPP, fato que não se encontra em consonância com os dizeres dos princípios da Educação em Direitos Humanos do Decreto $n^{\circ}$. 08/2012:

A Democracia na educação: o Direito Humano e a Democracia alicerçam-se sobre a mesma base-liberdade, igualdade e solidariedade. [...] desenvolvem continuamente por meio de participação. No ambiente educacional, a democracia implica na participação de todos/as os/as envolvidos no processo educativo. [...] e o diálogo interdisciplinar. Como se trata da construção de valores éticos, a Educação em

\footnotetext{
${ }^{4}$ Informações extraídas do Projeto Político-Pedagógico de 2012 fornecido pela instituição escolar.
}

Revista Educação Online, n. 19, jun-ago 2015, p.68-83 
Direitos Humanos é também fundamentalmente vivencial, sendo-Ihe necessária a adoção de estratégias metodológicas que privilegiam a construção prática destes valores. Tendo uma perspectiva de globalidade, deve envolver toda a comunidade escolar: alunos/as, professores/as, funcionários/as, direção, pais/mães e comunidade local. (BRASIL, 2012, p.10)

A base norteadora dos novos princípios da educação já contempla que, para uma mudança no modelo educacional vigente do país, faz-se necessária a integração entre a comunidade escolar e os demais agentes sociais, também responsáveis pelo desenvolvimento dos educandos.

Os dados mais significativos, obtidos por meio da análise documental, do livro de registros do histórico escolar relacionados aos dados das entrevistas, denotam que a maioria das famílias é constituída pela presença apenas da mãe como provedora da casa, sendo que há ainda o caso de quatro crianças que residem em instituições de abrigo de menores, denominada Casa Lar, estabelecimento que recebe crianças que tiveram por ordem judicial o afastamento de sua família, por abusos e maus tratos. Nesse sentido, há diferentes padrões de famílias na turma investigada, o que demandou diversas estratégias para compreensão da realidade dos sujeitos, pois, como consta em relatório do documento do histórico escolar, alguns dos alunos não têm nenhum parente consanguíneo responsável participante de sua vida, sendo assim, são cuidados e orientados pelos profissionais da Casa Lar.

Nogueira e Nogueira (2002) ressaltam que, mesmo entre famílias pertencentes à mesma classe social, há diferenças no envolvimento familiar no que tange ao desenvolvimento educacional de seus filhos, portanto, para uma constatação mais clara das influências da família no desempenho escolar de seus filhos, seria necessário, conhecer as relações entre os membros familiares e o sujeito receptor, neste caso, o estudante.

\section{Da entrevista semiestruturada}

A primeira questão da entrevista teve como intuito compreender a dinâmica que ocorre na escola, no sentido de descobrir a relação que os docentes têm com o estabelecimento escolar: Há quantos anos atua na rede de ensino? E neste estabelecimento? Das respostas obtidas, apenas dois professores afirmaram ser efetivos da instituição; os outros cinco docentes possuem um vínculo empregatício 
pelo processo seletivo simplificado (PSS), ou seja, não há um vínculo prolongado com o estabelecimento escolar, dificultando a relação de proximidade entre os agentes educacionais e a comunidade.

A importância da relação entre professor e escola é citada por Nóvoa (2013) com base no trabalho de Labaree (2000), o autor relata que a relação de ensino e aprendizagem depende em parte da cooperação e vontade do aluno. Ainda alerta sobre uma situação, que denominou de "ausência de sociedade", para compreender melhor as circunstâncias que permeiam a vida social dos alunos, dizendo que, "os docentes devem ser formados, não só para uma relação pedagógica com os alunos, mas também para uma relação social com as comunidades locais" (NÓVOA, 2013, p.229).

Esse fato se torna relevante para a compreensão dos docentes frente ao habitus e o campo da sua profissão, como atuam, habitus, e o estabelecimento aonde atuam, campo (BUSETTO, 2006). O reconhecimento desses termos criados por Bourdieu, permite aos docentes compreender o poder dos jogos que ocorrem dentro do ambiente aonde trabalham, para identificarem sua prática e, a partir de então, refletir sobre as situações escolares.

A segunda questão teve o intuito de conhecer a dinâmica em sala de aula, segundo a visão de cada docente. Portanto, lhes foi perguntado, qual o comportamento e a aprendizagem dos alunos da turma do sétimo ano? Os resultados apontaram que todos os docentes apresentaram o mesmo ponto de vista em relação à questão. Entre as falas, a mais expressiva, que denota essa similaridade, foi relatada pela docente P4: "Indisciplinados, desinteressados, desmotivados, não se interessam pela aprendizagem, o que compromete a aprendizagem, o ambiente da sala não é adequado para aprendizagem".

Tal realidade relatada pelos docentes pode ter origem em diferentes fatores. Dutercq (2013) descreve que os conflitos que ocorrem em sala de aula, em geral, são levados pela divergência de interpretações de situações vividas pelos grupos professores/alunos dentro da escola. Porém, esses conflitos, "referem claramente à transmissão dos saberes, mas a isso se acrescentam elementos internos, próprios da situação, e externos, vindos daquilo que ocorre no estabelecimento ou daquilo que ocorre nos outros lugares de vida dos alunos" (p. 170), sugerindo que as 
atitudes relatadas pelos docentes como agressivas e desrespeitosas podem ser desencadeadas por fatores internos ou externos a situações escolares.

É justamente devido às transformações sociais, que os princípios da Educação em Direitos Humanos têm como base permitir que grupos e países em condições sociais e econômicas desiguais, possam mudar essa realidade e criar oportunidades de mudança, principalmente, na área da educação (BRASIL, 2012).

Questões três e quatro: O que você apontaria como fator de influência no comportamento e na aprendizagem dos alunos? Acredita que a atuação da família no desenvolvimento do aluno influencia a sua prática pedagógica?

Buscava-se identificar se os professores atribuiriam as dificuldades enfrentadas na escola, como desrespeito e violência, a uma relação entre família e equipe escolar. Durante a análise dos dados, verificou-se que as respostas para ambas as questões apresentavam muitas similaridades, portanto, as falas foram analisadas e interpretadas em conjunto, resultando em uma só análise.

A "estrutura familiar" foi uma palavra que apareceu em todas as falas dos entrevistados. Dentro do contexto mencionado pelos docentes, entende-se por essa expressão algo que ocorre dentro do desenvolvimento familiar e se reflete na escola.

Em trabalho desenvolvido por Abdalla (2005), identificou-se certa resistência, por parte dos professores, em refletir sobre a realidade. Eles creditavam a culpa de todos seus problemas profissionais aos alunos, às famílias e à instituição em que lecionavam. Porém, ao reconhecerem o "campo de poder", encontraram meios para mudanças efetivas, como descreve Abdalla, ao citar Bourdieu: "[...] compreender o 'campo de poder' de suas escolas - 'o campo de suas instâncias de reprodução e consagração'. Campo que estabelece uma 'estruturadas relações de forma simbólica"' (BOURDIEU, 1998, p. 118 apud ABDALLA, 2005, p.390).

Os professores investigados não demonstram em suas falas um reconhecimento dessas relações, impossibilitando um enfrentamento da realidade, que, em parte, pode estar relacionada com a falta de vínculo com a escola, caso de cinco dos sete entrevistados, num modelo empregatício, que os desvincula, ano após ano, do mesmo estabelecimento escolar. Nogueira e Nogueira (2002) também ressaltam que há de se conhecer mais profundamente as relações familiares, para que se possa atribuir o comportamento dos filhos a um reflexo da vivência familiar. 
Outro detalhe importante sobre a visão dos docentes em relação à interferência familiar, em seu trabalho pedagógico, foi citado pela P7:

Com certeza, pois passo a maior parte do tempo realizando funções que não caberiam a mim, devido à falta de disciplina dos alunos, entre outras coisas, como verificar se o aluno é faltoso, se estão chegando fora do horário, controle de uniforme, alunos que estão fora da sala de aula por indisciplina, se os pais tomassem conta de alguns detalhes, eu poderia me ocupar com a minha função mesmo.

Essa fala remete não apenas à relevância que docentes atribuem à família, mas também a uma "carga" que esses profissionais parecem carregar em relação ao desenvolvimento escolar dos alunos.

A instituição escolar, ao longo de sua história, acabou adotando uma postura de resolver seus próprios conflitos. Segundo relato dos docentes, a equipe escolar adota uma postura de trabalho de distanciamento entre a prática pedagógica e as eventualidades que ocorriam na comunidade local. Hoje, a instituição escolar assume os mais diferentes papéis sociais, entre os quais, resolver as mais diferentes problemáticas sociais (NÓVOA, 2013).

Talvez, essa transição entre uma escola fechada, tradicional, para outra redentora das problemáticas sociais possa ter, tornando os docentes responsáveis, de certa forma, pelo desenvolvimento escolar e social dos alunos (NÓVOA, 2013). A sociedade vem criando uma situação, na qual os profissionais da educação podem se sentir desprepados para assumir essa função.

Nogueira e Nogueira (2002), ao citarem o trabalho realizado por Bourdieu, descrevem que os profissionais da educação esperam de seus estudantes comportamento e atitudes compatíveis com o ambiente escolar, independente de sua idade, devendo saber cumprir as regras da "boa educação", algo que, segundo os autores, seria um "julgamento cultural" (p.21). E de fato, essa constatação foi relatada pela docente $\mathrm{P} 1$ : "não têm comportamento de civilidade, a falta de princípios e valores familiares e a falta de regras mais firmes em relação à conduta da escola". Entretanto, essas exigências só podem ser plenamente atendidas por quem foi socializado previamente na família nesses mesmos valores (NOGUEIRA; NOGUEIRA, 2002).

Há nesse discurso, certa incoerência, uma vez que os próprios docentes afirmaram que seus estudantes apresentam uma de falta de estrutura familiar, ou seja, esperam que os estudantes demonstrem comportamento mais adequado, 
mesmo que estejam desprovidos de um aparato familiar. Sobre a relação familiar no que tange o desempenho escolar de seus filhos, Bourdieu (1998) ressalta que as famílias despendem tempo e atenção com o estudo de seus filhos, de acordo com as possibilidades de retorno que este estudo pode vir a proporcionar à estrutura econômica da família (NOGUEIRA; NOGUEIRA, 2002).

Lahire apud Nogueira e Nogueira (2002) observa a necessidade de conhecer as relações entre pais e filhos no seio familiar, para compreender como o habitus e/ou os capitais dos pais são repassados aos filhos, de modo a interferir positivamente no desenvolvimento escolar. Além disso, a equipe escolar deve levar em consideração que a experiência escolar, para alguns alunos, é estranha, por não fazer parte do habitus familiar a disponibilidade de capitais culturais exigidos pela escola (BUSETTO, 2006) quanto a isso, como sugere a professora P1, em sua fala na questão anterior, "não apresentam comportamento de civilidade".

Diante das angústias que todos os decentes parecem demonstrar, 0 reconhecimento de seu próprio habitus no ambiente escolar poderia ser uma das formas de mudança dessa realidade. Abdalla (2005, p.397) descreve que, quando os sujeitos incorporaram sua maneira de "ser" e "estar" na profissão, permitem que ocorra a reflexão e transformação de sua prática docente.

A análise documental do projeto político-pedagógico sugeria planos de ação, com o intuito de integrar a família no âmbito escolar. Nesse sentido, a questão cinco teve por finalidade verificar se as ações propostas no PPP ocorriam de fato na instituição: Neste estabelecimento ocorre interação entre família/escola/professores? Como?

Os professores entrevistados afirmaram que a questão da relação familiar com a escola não é um episódio frequente e não ocorre de maneira adequada, como relatam os professores $\mathrm{P} 1$ e P2: "A participação dos pais, por si só, nunca vi, mas acredito também que deveria haver um papel da escola nessa interação, e aqui isso não ocorre com frequência". O docente D acrescenta: "Ocorre com dificuldade, pois é difícil fazer com que venham à escola, e existe uma distância entre o corpo docente e a comunidade".

A importância dessa relação mais próxima entre família-escola é discutida por diversos autores, entre eles, Vygotsky (1998, p.87) que diz:

a educação recebida, na escola, e na sociedade de modo geral cumpre um papel primordial na constituição dos sujeitos, a atitude de pais e suas práticas de educação 
são aspectos que interferem no desenvolvimento individual e consequentemente no comportamento da criança na escola.

Vygotsky (1998) ressalta que não só as relações familiares, mas o contexto geral social no qual o sujeito está inserido, servem como base para o desenvolvimento educacional das crianças.

Voltando ao discurso dos professores P1 e P2, fica evidente que ocorre por parte dos professores um questionamento sobre o papel da equipe escolar em relação à temática da família na escola. Portanto, a equipe escolar deve realizar medidas que aproximem a cultura escolar da cultura de origem do aluno (NOGUEIRA; NOGUEIRA, 2002).

Nesse contexto, a escola assume um papel de intermediadora de ações que possibilitem que os princípios da Educação em Direitos Humanos vinculem a escola como promotora de atitudes valorativas de ações e vivências de seus integrantes. Os docentes participantes desta pesquisa não observam essa valorização no estabelecimento pesquisado, como sugere a resposta da professora P5, sobre relação família/escola e docentes:

não é muito frequente, pois os pais só aparecem na escola quando são chamados pela indisciplina dos filhos, e é difícil conseguir conversar com os pais, porque, quando aparecem na escola, os professores estão em sala de aula, e somente na hora-atividade é que conseguimos conversar.

Essa questão foi levantada por outros três docentes, que consideram a horaatividade um momento inadequado para resolverem conflitos de sala de aula.

Porém, segundo Lei n. 11. 738: 08, que regulamenta a jornada de trabalho dos docentes, estipulou-se uma carga mínima de um terço a atividades extraclasse, que, de acordo com a Secretaria de Educação do Paraná ${ }^{2}$, são destinadas ao planejamento, coordenação e avaliação do trabalho didático. Logo, seria possível utilizar esse momento para atender a família e os alunos, tornando esse momento também oportuno para tal enfrentamento.

O princípio da democracia na educação da Educação em Diretos Humanos confere respaldos às escolas, o que deixa evidente que as práticas e valores sociais devem estar pautados em uma colaboração coletiva, não incumbindo a nenhum

\footnotetext{
${ }^{5}$ Texto disponível no site oficial da Secretaria de Estado da Educação. Disponível em: http://www.educacao.pr.gov.br/arquivos/File/instrucoes2015_sued_seed/instrucao00115sued_seed.p df
}

Revista Educação Online, n. 19, jun-ago 2015, p.68-83 
setor social mais ou menos responsável pelo desenvolvimento e inserção social das crianças na sociedade (BRASIL, 2012).

Como a maioria dos professores entrevistados possui uma ampla experiência escolar, em várias instituições de ensino, a questão seis buscou investigar se os docentes evidenciaram, ao longo de sua trajetória profissional, ações que contemplassem a relação entre escola e família. Durante sua trajetória como docente, conhece ou vivenciou experiências de integração da família e comunidade na escola?

Com a exceção da professora P5,que relatou ação positiva: "Já, no estado mesmo, todas as festas comemorativas e a semana cultural são abertas, e convocados os pais para participarem", os demais afirmaram não terem conhecimento desse tipo de ação nas instituições públicas.

Essa realidade pode estar pautada no que Nóvoa (2013) chamou de estruturas burocráticas, corporativas e disciplinares, que impediram por muito tempo as ações locais, ou seja, atividades consideradas importantes para a vizinhança localparticipar do desenvolvimento escolar.

Considera-se que as propostas educacionais se pautam nos Direitos Humanos, cabe às instituições de ensino, juntamente com a equipe escolar e a comunidade, criar condições que permitam que os estudantes sejam construtores de seus conhecimentos, seguindo os objetivos da EDH, tais como, incluir os alunos na construção organizacional da instituição, promover atividades que envolvam situações da realidade vivenciada pelos alunos, entre outras, o que só é possível, quando todos os agentes sociais mencionados se articulam e possibilitam que 0 princípio da EDH de democracia na educação de fato exista (BRASIL, 2012).

\section{Considerações finais}

Como resposta às indagações formuladas no início do trabalho, a investigação de campo tornou possível um contato mais próximo com os agentes educacionais, permitindo conhecer a realidade das inter-relações escolares. Com o auxílio do Projeto Político Pedagógico e mediante os discursos dos professores participantes da pesquisa, foi possível constatar que não há, até o momento, projetos concretos que correspondam às expectativas sobre a temática. 
Segundo os dispositivos legais e norteadores utilizados aqui, as relações comunidade, família e escola são sugeridas como a forma mais adequada de possibilitar as condições favoráveis de aprendizagem e de sucesso escolar, porém, com a utilização da metodologia empregada neste trabalho, é possível aferir que, apesar de os professores concordarem que o envolvimento familiar interfere no ensino-aprendizagem, ainda não há um trabalho efetivo para contemplar essa ação.

Em relação às práticas pedagógicas, é possível constatar que não há, até o momento, no estabelecimento investigado, uma democracia educacional, uma vez que essa é construída através do plano político pedagógico, com ações elaboradas para contemplar a Educação em Direitos Humanos, com a participação efetiva da equipe pedagógica e comunidade, o que, segundo os entrevistados não estava ocorrendo.

Diante da literatura e do dispositivo legal empregado, nota-se que o papel da família na escola é considerado como um fator importante para o sucesso escolar dos alunos; contudo, com os dados coletados nesta pesquisa, é possível pontuar que, não apenas os docentes, mas toda a equipe escolar precisa reconhecer seu próprio habitus dentro do ambiente escolar, para que se possam promover mudanças na gestão educacional, no sentido de permitir uma aproximação mais efetiva com a família.

Pesquisas dessa natureza podem fornecer subsídios para compreendermos como a equipe pedagógica pensa e age com relação aos conflitos que enfrentam em seu dia a dia, o que nos permite uma reflexão sobre as reais necessidades educacionais, tendo em vista os efeitos que a proximidade família-escola pode trazer para o processo de ensino-aprendizagem.

\section{Referências bibliográficas}

ABDALLA. M de F. B. A pesquisa-ação como instrumento de análise e avaliação da prática docente. Revista Ensaio: aval. Pol. Públ. Educ., v.13, n.48, p.383-400, jul-set 2005.

BRASIL. Conselho Nacional de Educação. Conselho Pleno. Parecer 08/02 Princípios da Educação em Direitos Humanos (EDH). Brasília, Pleno do Conselho Nacional de Educação, 2012, p.1-18. Disponível em: $<$ http://portal.mec.gov.br/index.php?option=com.content\&id=17631\&mid=866>. Acesso em: 28/07/2014.

BRASIL. Lei $n^{\circ} 11.738$ de 16 de julho de 2008. Regulamenta disposições constitucionais transitória para instituir o piso salarial profissional nacional para os 
profissionais do magistério público da educação básica. Diário Oficial da República Federativa do Brasil, Brasília, $2008 . \quad$ Disponível em<http://www.planalto.gov.br/ccivil_03/_ato2007-2010/2008/lei//11738.htm>. Acesso em 15/03/2015.

BUSETTO, A. A Sociologia de Pierre Bourdieu e sua análise sobre a escola. In: CARVALHO, A.B.; SILVA, W. C. L. Sociologia e educação. Campinas: Avercamp, 2006. p. 113-33.

DUTERCQ, Y. "Pluralidade dos Mundos e Cultura Comum: professores e alunos à procura de normas consensuais". In: TARDIF, M.; LESSARD, C. O Ofício de professor: história, perspectivas e desafios internacionais. $5^{\mathfrak{a} e}$ ed.Petrópolis: Vozes, 2013. p. $169-80$.

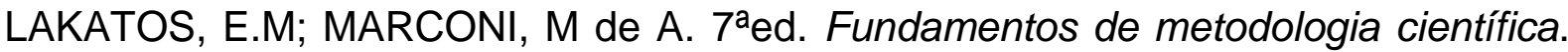
São Paulo: Atlas, 2010.

MORAES, R; GALIAZZI, M do C. Análise textual discursivo. 2ª̃ed. ljuí: Ed. Unjuí, 2011. p.139-169.

NOGUEIRA, M. A.; NOGUEIRA, C. A sociologia da educação de Pierre Bourdieu: limites e contribuições. Revista Educação e Sociedade, Ano XXIII, n. 78, 2002, abr 2002. Disponível em:<http://www.scielo.br/pdf/es/v23n78/a03v2378.pdf>. Acesso 20/08/2014

NOGUEIRA, M.A. Família e escola na contemporaneidade: os meandros de uma relação. Revista Educação e Realidade, v. 31, n.2, p. 156-170, 2006. Disponível em: $<w w w . s e e . u f r g s . b r / e d u c a c a o e r e a l i d a d e / a r t i c l e / v i e w / 6850>$. Acesso em: 20/08/2014.

NÓVOA, A. Os professores e o "novo" espaço público da Educação. In: TARDIF, M.; LESSARD, C. O ofício de professor. história, perspectivas e desafios internacionais. 5ed.Petrópolis: Vozes, 2013. p. 217-233.

SAVIANI. D. Pedagogia histórico-crítica: primeiras aproximações. 4ㄹed. Campinas: Autores Associados, 1994.

VYGOTSKY. L.A.S. Formação social da mente. São Paulo: Martins Fontes, 1998.

ZANTEN, A. A influência das normas de estabelecimento na socialização profissional dos professores: o caso dos professores dos colégios periféricos franceses. In: TARDIF, M.; LESSARD, C. O ofício de professor: história, perspectivas e desafios internacionais. 5ªed.Petrópolis: Vozes, 2013. p. 200-216. 